\title{
1. Understanding access to things: a knowledge commons perspective
}

\section{Michael J. Madison}

\section{INTRODUCTION: THE SEVERAL CHALLENGES OF ACCESS AND THINGS}

This chapter describes a problem concerning things of different sorts, a problem of law and public policy that we call access. The chapter explores the related ideas of access to things characterised as knowledge resources and shared governance of those resources, often known as commons. Access to knowledge resources is, in one central sense, a question of knowledge sharing. Knowledge resources consist of many types and forms. Some are old; some are new. Some are tangible or material; some are intangible or immaterial. Some are singular; some are reproduced in copies. Some are individuated or unique; some are collected or pooled. Some are viewed, used or consumed only by a single person; for some resources, collective or social consumption is the norm. In any of these settings, having access to the resource means somehow participating in creating, using or transferring the knowledge embedded in or represented in the resource. Knowledge is shared.

Any given resource, or thing, often has multiple attributes along the dimensions described above, depending on whether one examines the resource's physical properties, its creative or inventive properties, or its natural, factual or ideational properties. Access questions are, accordingly, diverse. That diversity is compounded by the fact that access is itself a property of a resource, in the sense that resource characteristics are, to a substantial extent, socially and culturally constructed, and in the sense that those properties may change over time, or may vary or be blurred depending on context. Boundaries among resources may likewise be blurred, or may evolve, or may vary with context.

By virtue of that diversity, investigating access to knowledge resources creates the risk of producing a conceptually fragmented and unhelpful landscape of theory and application on a resource-by-resource basis. This 
chapter suggests that the investigation of access to knowledge resources may be unified under the umbrella concept of knowledge commons, the study of governance of shared knowledge resources. It presents a framework for understanding knowledge commons and illustrates its application to several questions of access to the material and immaterial dimensions of specific knowledge resources. It offers, in short, a preliminary way into systematically answering the question: in this day and age, what are things?

\section{ACCESS TO THINGS AS GOVERNANCE}

The concept of "access" is meaningful only with respect to some person or people attempting to interact with some resource, which may be a space, a place or some material or immaterial "thing". We tend to think of things and humans as distinct, and this chapter will accept that division. But things may be subjects as well as objects in the equation above. Not only do people interact with things, but a thing may interact with another thing, or one resource with another. In attempting to understand the character of access, therefore, one must simultaneously attempt to understand the situated character of both its object and its subject. Put differently, the subject/object distinction, or the social/ technical distinction, is worth noting but not worth preserving at all costs. Both in general, from a theoretical perspective, and specifically, in any concrete context, one should ask not only "access by whom? (or by what?)", "access on what conditions?", "access relying on what capabilities?" and "access for what purpose?", but also "access to what?", "access where?" and "access when?" Access is a form of participation in the resource; the resource and its uses are mutually constitutive.

The overlapping and intertwined character of questions about access and resources suggests that access is not a concept that stands alone, independent of a resource as such, but instead exists as an attribute of that resource. Related concepts describing the intertwining of behaviours and things have been referred to as "entanglements"1 and as "structures of participation". ${ }^{2}$ The character of access inheres in definitional and interpretive questions that surround the provision of a resource and its distribution, consumption, re-use and preservation. To ask "what is a

1 Ian Hodder, Entangled: An Archaeology of the Relationships between Humans and Things (John Wiley \& Sons 2012).

2 Joe Karaganis (ed.), Structures of Participation in Digital Culture (Social Science Research Council 2007). 
resource?" or, somewhat more concretely, "what is a thing?" is simultaneously to ask "who participates in construction of the resource?", "for what purpose?" and "on what conditions?"

Law and public policy concerns are central to fully and fairly framing those questions, and legal frameworks grounded in chattel property, real property or intellectual property (IP) may guide responses. But those responses may also depend wholly or in part on extra-legal normative frameworks, on history, custom and on physical properties of the resource. The combination of those frameworks that are deemed relevant to construction of a resource (that is, constitution and interpretation of that resource and its physical, social, cultural and legal properties) is termed governance.

In this preliminary and provisional account of governance, little depends on clear or necessary distinctions between land or other natural resources and goods, or between immaterial and material goods in particular, or between intangible and tangible things in general. Little depends on distinctions noted in the Introduction between singular and pooled goods, between unique goods and those that are mass-produced or copied, or between individual creation and consumption, or social and shared use. And little depends on distinctions between "natural" things, which exist in the social and/or natural worlds, and "legal" things, such as patentable inventions, which exist to provide rough correspondence between those phenomenal worlds and the world of legal practice. ${ }^{3} \mathrm{~A}$ book is a material object that is subject to a governance investigation with respect to its sources and its impacts; 4 a copyrighted work of authorship is an immaterial object that calls for a similar and related but distinct inquiry. In each instance, the idea of governance provides a common framework for investigating the specific attributes of a particular resource and later synthesising the results of those investigations into a broader understanding of access and resources in general. As in the case of the book and the work of authorship embedded in that book, the relationship between material aspects of a resource and immaterial aspects of that resource is often a central question.

It is entirely possible and appropriate to ask governance questions with respect to any and all resources, but in this chapter I am concerned only with what I call knowledge resources, legal and natural "things" that comprise the worlds of innovation (including science and technology)

3 See Michael J Madison, 'Law as Design: Objects, Concepts, and Digital Things' (2005) 56 Case W Res L Rev 381, for an elaborate account of the constitution and construction of legal "things".

4 At least, that is the historical and conventional understanding of the book. 
and creation (including literature, music, visual arts and the like), and their legal analogues, primarily the patentable "invention" and the copyrightable "work of authorship". I have previously unified these fields under the broad heading of knowledge law, 5 and I rely on that framework here as well. It is tempting to treat knowledge or information as immaterial or intangible things, but both to give full credit to the governance concept and to appreciate the nuanced character of knowledge and information in the world, the intangible/tangible distinction should be and is treated as a governance question to be asked and investigated rather than as a dichotomy to be assumed. In practice, knowledge may take important material forms. ${ }^{6}$

Moving from the abstract to the concrete, consider the following governance-based critique of a specific problem of resource production and access in the domain of copyright law. In a well-known and widely circulated investigation of a case of social norms guiding the production of creative work, to the exclusion of a possibly applicable set of formal IP norms, Dotan Oliar and Christopher Sprigman described a robust system of norms of production, distribution and access of jokes among stand-up comedians in the US. ${ }^{7}$ Oliar and Sprigman observed that jokes developed and told by stand-up comedians could be characterised as copyrighted works of authorship. They further observed that stand-up comedians almost never assert formal copyright claims against one another with respect to those works, despite abundant and legitimate concerns that "joke stealing" by competitor comedians might lead to the underproduction of new, creative jokes.

Investigating further, they documented the emergence and evolution of a pattern of strong social norms among stand-up comics that counselled strongly against "joke stealing". Ideas for jokes were freely and fully shared among comics (who often toured and performed in the same

5 See Michael J Madison, 'Knowledge Curation' (2011) 86 Notre Dame L Rev 1957; Michael J Madison, 'Beyond Invention: Patent as Knowledge Law' (2011) 15 Lewis \& Clark L Rev 71; Michael J Madison, 'Beyond Creativity: Copyright as Knowledge Law' (2010) 12 Vanderbilt J Ent \& Tech L 817; and Michael J Madison, 'Notes on a Geography of Knowledge' (2009) 77 Fordham L Rev 2038.

6 See Nathalie Jeremijenko, 'Delusions of Immateriality', presentation at Doors 6 Lightness (November 2000), available 30 March 2016 at http://museum. doorsofperception.com/doors6/doors6/transcripts/jeremijenko.html (describing "tangible information strategies").

7 Dotan Oliar and Christopher Sprigman, 'There's No Free Laugh (Anymore): The Emergence of Intellectual Property Norms and the Transformation of Stand-Up Comedy' (2008) 94 Va L Rev 1787. 
venues, facilitating the sharing); the specific forms of jokes were off limits to competitors. Oliar and Sprigman observed that the evolution of social norms among comedians was intertwined with the evolution of the content of stand-up comedy itself. During the twentieth century, they concluded, stand-up comedy shifted from an earlier focus on "jokes" to "humorous stories", often told from the perspective of the comedian himself ${ }^{8}$ or about the comedian, or both. The shift from joke-based comedy to narrative comedy reduced the risk of "joke piracy", because a competing comedian would usually find that audiences would not laugh at the same story told "inauthentically".

Framed in this way, Oliar and Sprigman's research on stand-up comics poses a conventional question about production of and access to creative works and knowledge (how will new creative things be produced if the producers cannot limit access to their works and appropriate returns via conventional IP tools?). They emerge with a novel response. Social norms of a copyright-ish sort offer a substitute for formal copyright law.

I have argued that this framing, while extremely useful as an antidote to the normative ubiquity of formal copyright law, is incomplete as an account of the production and distribution of creative things. My question concerning stand-up comedy is not whether formal IP law is doing the work that public policy assumes that it does, but instead how the production and distribution of stand-up comedy is governed. This re-framing introduces several additional questions and responses, one of which is particularly noteworthy in the context of the present interest in "things", whether material or immaterial. How did stand-up comics make their money?

In earlier work, ${ }^{9}$ I argued that formal IP rights may nonetheless have played a key role in creating markets for stand-up comedy, and norms may have been relatively unimportant as incentives to create. The early 1960s, which saw the beginning of narrative and perspective-oriented comedy, also witnessed comics starting to do what authors have done for centuries, using the tools that copyright has long recognised as intrinsic to markets for creativity. They sold copies of their works. And they sold lots of them.

LPs by a wide variety of comedians earned gold record recognition during the 1960s and 1970s ("gold" meaning certified by the Recording

\footnotetext{
8 Stand-up comedians have long been and mostly remain overwhelmingly male.

9 The following five paragraphs appeared previously in substantially similar form in Michael $\mathrm{J}$ Madison, 'Of Coase and Comics, or the Comedy of Copyright' (2009) 95 Va L Rev in Brief 27 (footnotes omitted).
} 
Industry Association of America as having sold 500,000 units). The first comic gold record was The Button-Down Mind of Bob Newhart, which was released in 1960 and was certified "gold" in 1962. Newhart's follow-up release, The Button-Down Mind Strikes Back, went gold in 1967. Other comics with gold records during the 1960s and 1970s included the Smothers Brothers (1966 and 1967), Bill Cosby (four gold records in 1966, two more in 1967, and one in 1968), Flip Wilson (1970), Cheech and Chong (four gold records during the 1970s), George Carlin (also with four gold records), Richard Pryor (four), and Steve Martin (two). This parade of top-selling records does not account for the many other LPs released by comics during the 1960s, including notable releases by Nichols and May, Stan Freberg, Carl Reiner and Mel Brooks, Dick Gregory and Jonathan Winters. In the 1970s, Robert Klein, David Steinberg and Lily Tomlin also released successful comedy albums.

The comedy recordings of the 1960s and 1970s, virtually all of which were characterised by the narrative comedy that emerged at the beginning of that era, were grounded partly in technology. The LP format that emerged as a technological standard in the late 1940s gave comics more time to talk. They took advantage of that opportunity by telling stories rather than one-liners. Oliar and Sprigman situate that development in a loose Demsetzian propertisation argument. Identifying and punishing thieves became easier. Story-telling discouraged commodification of comedy and discouraged theft. Yet comics may have turned to storytelling not to avoid appropriation of their work by others but to enable appropriation for themselves. Story-telling was not only technologically feasible; it also sold extremely well.

What may be referred to as "the comedy album phenomenon of the 1960s" was also grounded solidly in economics. The copyright system imagines that creators will appropriate the value of their work by charging consumers to access it; it imagines that the work gets shared via distribution of copies. Selling records worked for comics as it worked for musicians, and as selling books worked for authors. Higher-tier comics made a decent living. Lower-tier comics were stirred to emulate their more famous and successful colleagues. Top-selling comedians were offered starring roles on television programmes and in Hollywood movies. By the late 1970s, comedy stars "had become the popular equivalent of rock stars". From the standpoint of comedy fans, records made comedy accessible to audiences that could not afford to attend live shows or did not want to.

This golden era faded during the 1980s with the rise of cable television and pre-recorded videocassettes. That means that the hypothetical market 
failure on which There's No Free Laugh is premised either has long been solved via conventional property mechanisms (if successors to LPs offered equal or better appropriability mechanisms), or that the specific combination of conventional property mechanisms and social norms that Oliar and Sprigman describe emerged more recently than they hypothesise (if appropriability declined). As with a re-assessment of the public-goods argument regarding jokes, this change in the historical account of markets does not make the emergence of a normative regime unimportant. But setting a system of social norms side by side with a conventional copyright-based appropriation regime colours the significance of both. Copyright markets may have served comics well.

Note, in short, that a full account of questions of production and distribution of this creative content and access to it - governance requires taking into consideration not only the immaterial dimensions of communicative behaviour among comics themselves, but also the materiality of the production of LP (and later cassette) copies of comedy recordings. It is tempting to suppose that the widespread availability of the recordings mattered little to the comics, because they had little to fear from possible appropriation of their work by ordinary consumers. But it is equally fair to suppose that generations of future comics were inspired to perform and may even have pursued their early careers precisely by emulating the performers whose work they heard on vinyl recordings. Access to the immaterial version of jokes, and re-use of that content, was governed - that is, limited - by an informal but robust system of social norms. Access to the material copy was governed by a market-based system of IP law together with chattel property law. Under that latter system, re-use of the jokes was at least tacitly encouraged, and such re-use may have been central to the propagation and production not only of specific jokes and funny stories but also of genres of stand-up comedy themselves. Anyone of a certain age in the 1960s and 1970s can probably recall telling and re-telling stories that they heard exclusively on LPs.

Governance of this material - jokes - means that production, access to and use of expressive content was constituted by a blend of social norms, by which stand-up comics participated in the production of the (immaterial) jokes themselves, and exchange-based and copyrightregulated markets for material things (LPs), by which both consumers and next-generation comics participated in the production of comedy as a genre and laughter as a social good. The case signifies an important and 
unexpectedly complex example of the changing construction and constitution of overlapping resources via law and social norms. ${ }^{10}$

To be clear, the argument in the preceding paragraphs is at least somewhat speculative. It does not follow directly from Oliar and Sprigman's work, and it is not the basis of my own independent research. At best, it is a single and possibly non-representative case illustrating the governance of certain knowledge resources. There is no reason to assume that the specific patterns of interaction among comedic joke creators, consumers and future comics laid out in those paragraphs are replicated elsewhere, and there is no reason to propose that those patterns themselves justify either preserving the current law and policy environment that sustains them now (or that sustained them in the past), ${ }^{11}$ or modifying that environment to ensure that comparable patterns are sustained in the future.

Law preservation and/or law reform require broader foundational sources of understanding. One should understand governance in a broad sense; that is, what access means with reference to knowledge resources in general, before moving forward with guidance regarding law and policy. One needs a method of integrating research and learning of a specific, contextual character with research from other, similar but distinct domains. One such method is described in the next section.

\section{KNOWLEDGE COMMONS: A RESEARCH FRAMEWORK FOR UNDERSTANDING GOVERNANCE AND THINGS}

The point of any research framework is to permit research and data collection to proceed under a common set of assumptions and questions, even if specific research methods and disciplinary foundations may vary

10 One could and perhaps should go further and note the construction of "spillover" resources in this process, such as personal privacy, via the blending of the immaterial and the material. During the 1960s and 1970s, many a listener relied on LPs of provocative comics to obtain access to "forbidden" material in the privacy of the home, away from parents and the broader community. That privacy fuelled continued demand for new material. Cf Julie E Cohen, 'A Right to Read Anonymously: A Closer Look at "Copyright Management" in Cyberspace' (1996) 28 Conn L Rev 981.

11 This would include copyright laws and policies that draw distinctions between ideas and expression, that limit protection to the intangible work of authorship, and that enforce rules of first sale and/or exhaustion with respect to lawfully produced tangible copies of those works. 
from researcher to researcher or field to field. The framework is neither theory nor model; strong theorising and modelling may follow the research but only light and tentative theorising, if any, should precede it. The point of the knowledge commons framework described below is that access to knowledge, in both material and immaterial forms, is an issue of knowledge sharing in institutional context. ${ }^{12}$ The question of access may begin with questioning the participatory, governance relationship between the individual and the thing (or the relationship between one thing and another thing), but it evolves quickly into questions about institutional character.

The framework as described is borrowed from a recent book entitled Governing Knowledge Commons. ${ }^{13}$ That book presents the framework and applies it to a set of case studies of institutions defined in part by knowledge-sharing practices with respect to one or more knowledge resources. While the framework is designed for application at the institutional level, referred to as commons, the intuitions and preliminary investigation that animated its development are applicable more broadly. Knowledge resources come in many forms - immaterial, material, flows as well as forms, and labour and skill and time as well as embodied creation. ${ }^{14}$ Knowledge sharing and knowledge retention are as acute and

12 The point of this chapter is primarily descriptive, but the claim about knowledge sharing in institutional context can be and has been adapted for normative purposes. See Gaëlle Krikorian and Amy Kapczynski (eds), Access to Knowledge in the Age of Intellectual Property (MIT Press 2010).

13 Brett M Frischmann, Michael J Madison, and Katherine J Strandburg (eds), Governing Knowledge Commons (OUP 2014).

14 Tangible things might themselves constitute copyrightable works. See Michael J Madison, 'Creativity and Craft' in Shubha Ghosh and Robin Paul Malloy (eds), Creativity, Law, and Entrepreneurship (Edward Elgar 2011). Moreover, knowledge resources might be constituted from flows of meaning among and within groups rather than from artefacts: "The personal vision of an author or creator, and the response of a reader or audience, may be best seen as part of a flow of meaning embedded in various intangible and tangible forms, including objects, rhetorics, and social and business practices. In many fields, subject matter favored by outsiders, amateurs, and hobbyists evolves into new domains of professionalism." Madison, 'Beyond Creativity' (n 5) 843. See also Martin Senftleben, 'Copyright and Creators' Interests - Rights and Remuneration in the Light of Bourdieu's Analysis of the Field of Literary and Artistic Production' (2014), available 30 March 2016 at http://papers.ssrn.com/sol3/ papers.cfm?abstract_id=2522855 (advocating for a re-interpretation of exceptions and limitations in copyright law as a law of creators' rights, derived from Bourdieu's theory of fields). A world in which knowledge is embedded in and via multiple and overlapping flows of meaning, instantiated in both material and 
important a set of law and policy problems as knowledge production. Access to knowledge resources is a fundamental part of governance solutions to that problem. The next section of this chapter applies parts of the framework, briefly, to a handful of examples and illustrations of access problems at the boundary of materiality and immateriality with respect to knowledge resources. The balance of this section gives a fuller account of the framework itself.

The knowledge commons framework builds on a series of related intuitions. Commons governance means knowledge and information management characterised by domains of managed openness and sharing of relevant resources, and the first intuition is that commons governance is in broad use in day-to-day practice in a variety of domains and across a variety of scales. Documenting evidence to justify that intuition is the first goal of the framework. The second intuition is that such structured openness in the management of both natural and cultural resources is likely to lead to socially beneficial and/or socially productive outcomes. Salient among the class of cases where commons governance is successful and sustainable are contexts where social interest in positive spillovers from bilateral, market transactions is high. Commons may sustain the production of spillovers when the market may otherwise not. Testing that intuition by applying the framework in a series of case studies is the second goal. The final intuition is that a standard framework for identifying and assessing commons across a variety of domains can support the development of more sophisticated tools for realising the potential for commons solutions in new institutional settings and for distinguishing commons solutions from other solutions in settings where some other approach, such as an approach grounded in proprietary rights, might be preferred. Applying the knowledge commons research framework is an exercise in analysing colloquial commons institutions, such as "scientific research" taken in the aggregate, in a nuanced way via comparative institutional analysis.

Examining constructed commons in the cultural context builds on the Institutional Analysis and Development (IAD) framework pioneered by

immaterial forms, may be a creative and innovative world. See Mihaly Csikszentmihalyi, Creativity: Flow and the Psychology of Discovery and Invention (HarperCollins 1996) (describing the psychology of creativity); and John Seely Brown and Paul Duguid, The Social Life of Information (Harvard Business Review Press 2000) (describing "ecologies" of innovation and innovation in firms). This note is intended only to be suggestive; the relationship among resources and outcomes is an empirical question. 
Elinor Ostrom and her colleagues, but it adds some important modifications. The IAD framework has been used principally to structure analysis of solutions to collective-action problems in natural-resource contexts (so-called action arenas, or action situations) such as forests, fisheries and irrigation systems. IAD analysis is premised largely on choice-processing, goal-oriented behaviour by self-interested individuals. It looks to explain sustainable collective action that produces measurable, productive results. The insight from applying the IAD framework to a large number of governance institutions and resources is that commons solutions can be as robust as market-oriented solutions to classic "tragedy of the commons" overconsumption dilemmas involving depletable natural resources. Shared governance can lead to sustainable fisheries and forests and to regular supplies of usable water.

The knowledge commons framework differs from the IAD framework in certain key respects. It does not assume the agency of rational, choice-selecting, self-interested individuals. It accepts the role of historical contingency and of inward-directed agents in the evolution of collective or commons institutions. At the front end of the analysis, it also requires understanding the contingency of the underlying resources themselves. Natural-resource commons largely take the existence of their resources for granted: fish, trees, water and the like. Knowledge commons identify resource design and creation as variables to be analysed. As cultural resources (that is, as forms of knowledge and information), patents, copyrights and underlying inventions, creations and data are shaped by a variety of institutional forces rather than by nature.

Critically, the knowledge commons framework does not assume that the relevant resources are rival and depletable. The knowledge commons framework generally assumes precisely the contrary: that intangible information and knowledge resources are non-rival, non-excludable public goods. The dilemma to be solved is not primarily a classic "tragic commons" overconsumption problem. Instead, it is more likely (in part) an underproduction problem and (in part) a coordination problem. In the absence of a governance mechanism to moderate consumption, producers of resources will fail to invest in creating new goods or in preserving them, either on their own or in combination with others, because of uncertainty regarding their ability (either individually or collectively) to earn returns that justify the investment.

Against that background, the knowledge commons framework proposes to undertake comparative institutional analysis by evaluating cases of commons resources via a series of questions, or clusters, to be applied in each instance. Several of these are borrowed or adapted from Ostrom's 
IAD framework. Some are developed specifically for the knowledge commons context. ${ }^{15}$

The case study investigation begins with a general description of the history and character of the problem that is being addressed by governance in the specific case or context. This may be an explanation that is internal to the governed institution(s) (the problems and explanations may emerge from stories told by participants, either today or historically or both), or an explanation that is external to the governed institution (such as the public-goods accounts of the rise of IP law).

One should ask whether the relevant resource or case is characterised from the outset by patent rights or other proprietary rights, as in the case of a patent pool, or by a legal regime of formal or informal openness, as in the case of public-domain data or information collected in a government archive. A particular regime might involve sharing data and information, or sharing rights in information, or sharing both. The character of the commons solution might involve coordinating holders of different IP interests or holders of different public-domain knowledge resources, for example.

Answering that question sets a default baseline against which a commons governance regime has been constructed. Within that regime, one next asks definitional questions. What are the relevant resources taking into account both tangible and intangible things; what are the relationships among these resources, the baseline and any relevant legal regime (for example, what a scientist considers to be an invention, what patent law considers to be an invention, and the boundaries of the patent itself are three related but distinct things); and what are the boundaries and constitution (membership) of the community or communities that manage access to and use of those resources? How is membership acquired (this may be informal, formal, or a blend of the two) and how is membership governed? What is good behaviour within the group, what is bad behaviour, who polices that boundary and how?

Next are questions concerning explicit and implicit goals and objectives of commons governance, if any such goals and objectives exist (it is possible that commons governance regimes emerge from historical contingency rather than via planning). Is there a particular resource development or management dilemma that commons governance is

15 A brief overview and schematic of the framework is available at http:// knowledge-commons.net/publications/gkc/research-framework/ (accessed 30 March 2016). 
intended to address, and what commons strategies are used to address that dilemma?

How "open" are the knowledge and information resources and the community of participants that create, use and manage them? Governing Knowledge Commons argues that commons governance regimes involve significance measures of resource and community sharing and openness. Their details, however, should be specified, along with their contributions to the effectiveness of commons. Some commons and commons resources have precise and fixed definitions of both resources and community membership. Or, either resources or membership or both may be more fluid, with boundaries defined by flexible standards rather than by rules.

A large and critical cluster of questions concerns the dynamics of commons governance, or what Ostrom refers to as the "rules-in-use" of commons: the interactions of commons participants and resources. Included in this cluster of questions are (1) details of stories of the origins, histories and operations of commons; (2) formal and informal (norm-based) rules and practices regarding distribution of commons resources among participants, including rules for appropriation and replenishment of commons resources; (3) the institutional setting(s), including the possibility that regimes are "nested" in larger-scale institutions and are dependent on other, adjacent institutions; (4) relevant legal regimes, including but not limited to IP law; (5) the structure of interactions between commons resources and participants and institutions adjacent to and outside the regime; and (6) dispute resolution and other disciplinary mechanisms by which commons rules, norms and participants are policed.

At this point it becomes possible to identify and assess outcomes. In Ostrom's IAD framework, outcomes are typically assessed in terms of the resources themselves. Has a fishery been managed in a way that sustains fish stocks over time? Do commons participants, such as the members of a fishing community, earn returns in the commons context that match or exceed returns from participation in an alternative governance context? In knowledge commons, resource-based outcome measures may be difficult to identify and assess. Sustaining the resources and their uses, individually or in combination, may be the point. In a patent pool, pooled resources may constitute components of larger, complex products that could not be produced but for the pooling arrangement that reduces transaction costs among participants. Outcomes take different forms. It may be the case that patterns of participant interaction constitute relevant outcomes as well as relevant inputs. Agency, in a manner of speaking, may be less important than identity; the group and its participants, in a 
particular institutional setting, may be ends as well as means. Levels of interaction and combination matter. Participant interaction in the context of a shared resource pool or group may give rise to (or preserve or modify) an industrial field or a technical discipline. In that specific case, such spillovers may be treated as relevant outcomes.

Having identified relevant outcomes, it becomes possible to look back at the problems that defined commons governance in the first place. Has the regime solved those problems and, if not, then what gaps remain? How do the outcomes produced by commons governance differ from outcomes that might have been available if alternative governance had been employed? On the other side of the assessment ledger, has commons governance created costs or risks that should give policy makers and/or institution designers pause? Costs of administration might be needlessly high; costs of participation might be high; and commons governance might offer a risk of negative spillovers that offsets the initial instinct that commons produce positive spillovers. A collection of industrial firms that pool related patents in order to produce complex products may produce those products but may also engage in anti-competitive, collusive behaviour. Commons governance may facilitate innovation; it may also facilitate stagnation, or worse.

\section{ACCESS TO THINGS FROM THE KNOWLEDGE COMMONS PERSPECTIVE: APPLICATIONS}

The knowledge commons framework directs questions to governance strategies with respect to those resources (and to the nature of openness and other resource attributes, for example) and to the character of individuals, groups and the state in navigating and implementing those strategies. Understanding the intertwining of people and resources in a specific setting, but in a way that learning from one case can be aggregated with learning from other cases, is precisely the point of the framework. But the framework as just presented may appear to be unhelpfully abstract. This section draws out some of its tools and themes in the context of specific applications, with a focus on elements of particular interest in the context of access to knowledge resources: the character of those resources themselves. The discussion does not attempt to apply the framework in all its details.

As specific cases are discussed, identifying and understanding the creation and governance of boundaries of various sorts, and movement (flows) of resources and people, become central. Access to knowledge resources generally presumes some degree of permeability or porosity 
with respect to a given resource, to relationships between one resource and another, and between one resource and a person or group. These may be examples of what Julie Cohen recently referred to as "semantic discontinuities"16 and what I described long ago as examples of the "discontinuous" world of analogue knowledge and information. ${ }^{17}$ Access and governance mean the intertwining of people and resources; resource identification and description mean the intertwining of what "is" and "is not" the resource. That intertwining may be represented by gaps, by overlaps, or by both.

The three cases summarised below each concern what may be the most problematic "thing" or resource in the landscape of knowledge law and policy: the work of authorship, known in some national copyright systems as the copyright work. Each of the cases below is just that, a report of a litigated dispute. The knowledge commons framework is not intended to be applied in detail at this level; it is intended to capture insights about institutional governance. Litigated cases, the bread and butter of the legal scholar's method, are used here for the sake of brevity and ease of illustration. Institutional lessons can be discerned by implication.

\subsection{Kelley v Chicago Park District: "Works" among Human-created and Natural Resources}

Works in the copyright context are unquestionably things or resources, and they are both intended to be shared and designed to be shared. They are, therefore, a prototypical resource for knowledge commons governance purposes. Works may be characterised in different ways at times and over time, ${ }^{18}$ but the idea of the work in any particular instance remains fundamentally the same. This is true both in the general sense that the idea of the work is meant to be the same across artistic disciplines, media and eras, and in the specific sense that, once a work has been created, it cannot (or at least should not) change. The work itself is static, even if the law permits authors, courts and others to re-characterise what it is. But, of course, things change. Art changes. Do works change? And if so, how?

\footnotetext{
16 Julie E Cohen, Configuring the Networked Self: Law, Code, and the Play of Everyday Practice (Yale UP 2012).

17 Michael J Madison, 'Complexity and Copyright in Contradiction' (2000) 18 Cardozo Arts \& Ent L J 125.

18 See Brad Sherman, 'What is a Copyright Work?' (2011) 12 Theor Inq L 99.
} 
Courts wrestle, in this sense, with the idea of the work as a boundary between static and stable works, on the one hand, and dynamic and changing works, on the other hand. This wrestling represents a blurry boundary between knowledge resources as creative form and creative flow, sometimes expressed as a boundary between culture and nature and as copyright's distinction between idea and expression. In each respect, governance of knowledge sharing animates and frames the questions and responses. For an illustration, consider a recent case involving gardens and landscapes.

In Kelley v Chicago Park District, ${ }^{19}$ the plaintiff, without question an established and successful artist, designed an elaborate and formal public flower garden known as "Wildflower Works" with the permission and participation of relevant public authorities. After a long period of maintenance of the garden and then disputes between the designer and the owner of the garden space, the owner, the Chicago Park District, made substantial modifications to the garden over the objection of the designer. The designer, claiming that the landscape design was an original work of authorship protected in copyright, sued for violations of the right to integrity of the work under the American Visual Artists Rights Act (VARA). Among the questions faced by the Court was whether the designed public garden was a "work of visual art", or a work of any kind, covered by the statute. The federal Court of Appeals for the Seventh Circuit, rejecting the plaintiff's claim, concluded in dicta that it was not.

The Court began by accepting (as the parties had) that the landscape design consisted of a painting or a sculpture, the categories of copyrightable expression that it most resembled, that is, a kind of artistic work, and then considered whether that work met the requirements of the statute as to originality and fixation.

The Court concluded that it did not. The Court worried that copyright here was asked to recognise a work that was "infinitely malleable". The Court concluded (in a questionable part of its reasoning) that the garden did not rise to the level of originality or stable fixation required by the law, because the living garden was subject to inevitable changes over time, and the changes were not the product of the plaintiff's authorship. So, while the Court itself gave little weight to the idea of "the work" as a thing in itself aside from the statute's other subject-matter requirements, originality and fixation, there is a boundary principle in play. That principle appears to depend on what I have called governance, and in

19635 F. 3d 290 (7th Cir 2011). 
particular on ideas concerning how the different forms of knowledge represented in this landscape design are shared.

In dicta the Court expressed scepticism that Wildflower Works should be treated as a painting or a sculpture, as the plaintiff argued; that is, that the design should be treated as a work in the first place. The Court's attention was directed to the material and physical elements of the garden, which are by definition open not only to human interaction (subject to possible restrictions on access to the park in which the design was set) but, more important, to interaction with other "things", leading necessarily both to change in the appearance of the design itself and to the emergence of new, natural things. The resource - the landscape design - is shared with another resource: nature. The malleability of the physical resource in those circumstances gives the work itself a fluid character that exceeds the limits accepted by copyright law. ${ }^{20}$ The Court wrote: "The Park District suggests that Wildflower Works is an uncopyrightable 'method' or 'system."'21 It continued: "Although Wildflower Works was designed to be largely self-sustaining (at least initially), it's not really a 'method' or 'system' at all. It's a garden.'22

Unpacking that last statement ("It's a garden"; therefore, by implication, it cannot be a work), the Court identifies a boundary between, yet also connects, multiple resources: static works and dynamic things, between static things and dynamic "processes" or "systems", between the static created work and the dynamic natural idea, and between the intangible "design" of this landscape and its material realisation. Traditional copyright law and its focus on the independent, intangible creative thing contrasts with deeper, organic processes that are revealed by nature, even while both perspectives on landscape design and gardens themselves are literally and physically present in one and the same place and space. The Court's answer to the challenge of distinguishing these things - "It's a garden" - is clearly inadequate, because it simply re-states the issue. Why is a garden not a work? Perhaps for the following reason: A work

20 One could analogise the landscape design not to a painting or to a sculpture but instead to an elaborate meal prepared by a trained chef. The chef, we know, is a kind of creator, working with natural and prepared ingredients, blending them in original and even expressive ways, anticipating their interaction with natural processes (such as heat and cold), and "fixing" the result in the form of the meal as presented at table. Yet it is widely understood (though not without some controversy) that neither the chef's techniques, the chef's recipes, nor the resulting meals are protected by copyright.

21 Kelley v Chicago Park District (n 19) 303.

22 Ibid. 
$q u a$ work is communicative and expressive, not simply functional. A work shares itself with humans. A work expresses the author's creativity and the audience's response; a work communicates the fact that humans produced it. ${ }^{23} \mathrm{~A}$ work is therefore governed, precisely because it is shared. Anything else - plants, flowers, animals and prepared food communicates (or may communicate) the fact that organic processes are primarily driving what we see and experience; the material character of the resource dominates its communicative, intangible character. One cancels out the other, rather than one complementing the other. Nature, in its physical state, is given.

Gardeners and landscape designers know that what appears to be "natural" often reflects deep and thoughtful engagement by humans. The vocabulary of giving is far from univocal: we may say that we receive gifts (from God, from nature, from others), that we have gifts (special skills) and that we share them. Often, the conceptual linkages embedded in those phrases go unrecognised and unexplored, as do linkages between gifts and agency. Characterising nature as a gift and as a source of gifts does not exclude human agency. To exclude gardening categorically from copyright amounts not only to excluding the effort and ingenuity of a particular author, but also the knowledge, practices, traditions and expectations of an entire field. That field may be human-directed and cultural; that field may be scientific and technological; that field may be spiritual and only partly known or knowable by humans. In the case of natural things and processes the work is therefore the locus of a governance debate about what is in copyright and what is beyond it, what is owned and marketable and what is accessible by others or by all, and on what terms. Nature no less than culture is a product of and part of processes of human engagement. ${ }^{24}$ Kelley may be critiqued on the merits of its legal analysis and result; it is useful nonetheless for its introduction to questions of access and governance.

23 See Abraham Drassinower, 'Copyright Infringement as Compelled Speech' in Annabelle Lever (ed.), New Frontiers in the Philosophy of Intellectual Property (CUP 2012) (arguing that a work subject to copyright is a communicative act).

24 See William Cronon, 'The Trouble with Wilderness; or, Getting Back to the Wrong Nature' in William Cronon (ed.), Uncommon Ground: Rethinking the Human Place in Nature (WW Norton \& Co 1995). 


\subsection{Massachusetts Museum of Contemporary Art Foundation, Inc v Büchel: Finished and Unfinished "Works"}

The idea of "the work" can tell us when a work is a "work" worthy of copyright contemplation, or is instead a draft, sketch or idea. In this sense, the work defines the trigger of copyright; it shifts the frame of governance. Before something becomes a work, copyright law does not apply; the material is preliminary and therefore freely shareable, used and experienced. Justin Hughes pursues this reasoning, in part, when he argues that copyright law should not protect tiny "microworks" because they are not works. ${ }^{25}$ In a related sense, a creative thing may emerge as a work from early or unformed effort, and in doing so it crosses a kind of copyright boundary. A copyright work sits at an intersection between complete control of both immaterial and material dimensions of the unfinished thing vested in its creator, on the one hand, and governance of the finished thing managed by a complex that includes not only the creator but also other individual, institutional and collective interests, on the other.

An art-world case illustrates. In Massachusetts Museum of Contemporary Art Foundation, Inc v Büchel, ${ }^{26}$ the plaintiff Christophe Büchel was a conceptual artist who commissioned the defendant, the Massachusetts Museum of Contemporary Art (MassMoCA), to install a large, complex and expensive conceptual sculpture entitled Training Ground for Democracy. MassMoCA agreed to bear the expense of the installation. The parties' contract failed, however, to provide sufficient detail regarding the project's final scope. During installation, Büchel made substantial changes to the project. Fearing that it would never recoup its installation expense via admission charges or otherwise, MassMoCA eventually suspended additional effort and opened the incomplete installation to public viewing. Training Ground for Democracy was intended to be an immersive experience; museum patrons would walk through the sculpture. MassMoCA included signage making it clear to patrons that the sculpture on display was not the completed work of the artist. Büchel nonetheless sued, both under the relevant provisions of VARA, § 106A of the US Copyright Act, ${ }^{27}$ for violations of his rights to integrity and

25 Justin Hughes, 'Size Matters (or Should) in Copyright Law' (2005) 74 Fordham L Rev 575.

26593 F. 3d 38 (1st Cir 2010).

2717 USC $\S 106 \mathrm{~A}$ (2012). 
attribution, and also under the public display portion of $\S 106$ of the Copyright Act.

With respect to both claims, MassMoCA argued that Büchel had not proved the existence of a "work" that triggered any obligations under copyright law. As Büchel himself acknowledged, from the artist's point of view the work of art here consisted of a specific kind of patrons' visual and physical experience of the creation. ${ }^{28}$ To MassMoCA, the presence or absence of a work was a kind of jurisdictional boundary. Until an author is done creating, copyright law is irrelevant. ${ }^{29}$ On this reasoning, an unfinished sculpture is not a work. The federal District Court for the District of Massachusetts agreed, but the Court of Appeals for the First Circuit did not. The latter court relied on the copyright statute's definition of "created", which applies, it held, to unfinished works. ${ }^{30}$ It held that Büchel's work fell within the scope of VARA as a "work of visual art", despite its unfinished state.

Form matters, one might simply say. Yet what remains unclear from the outcome of the case is whether what matters is the state of the intangible or immaterial - the artist's creation - or the state of the tangible or the material - the physical space, partly occupied by elements of the sculpture. The shape of the governance applicable here is murky. On a purely formal reading, the Appellate Court's interpretation of the statute almost certainly is incorrect if the idea of the work is to be independent of fixation, and if there is any jurisdictional boundary between creativity to which copyright attaches and creativity that lies outside it. ${ }^{31}$ Of course, such a boundary may not exist, which means that the Court was correct after all; a broader governance approach, which relates the immaterial and material dimensions of the artist's vision and effort, the museum's investment and the audience's experience, teaches (perhaps) that the Court came to the appropriate conclusion.

The fact that Büchel sued under VARA, the limited version of moral rights protection available under US copyright law, is the clue that unlocks the overlapping and shared character of these relationships. US

28 See 'MassMoCA's Lawsuit' (The ART Law Blog, 27 May 2007), available 30 March 2016 at http://theartlawblog.blogspot.com/2007/05/mass-mocaslawsuit.html (blog post written by Büchel's counsel).

29 Before the 1976 Copyright Act took effect, this was indeed the case in the US. With few exceptions, copyright applied only to published works.

3017 USC $\$ 101$ (2012) (defining "created").

31 The statute clearly applies to things that are completed in pieces, such as movements of a symphony or chapters of a novel. It is less clear that the statute applies, or should apply, to every successive stroke of a pen or brush. 
copyright law only reluctantly accommodates authors' rights, preferring instead to emphasise economic rights according to the presence or absence of a work. Governance in such a context is often linear and formal; the question is simply whether the intangible character of a work has been exploited inappropriately in the market, and usually commercially. But authors' rights (or droit moral) more fully manage intersections between the practices and expectations of artists and authors, on the one hand, and the practices and expectations of other claimants and institutions, on the other, and that management, or governance, is expressed largely through control of the physical manifestation of the author's vision. The fact that droit moral extends control over physical resources is ironic, perhaps, given the fact that justification for those rights originates in the idea of the vision of a work that derives from an author's (intangible) identity or personality. The governance expressed in this case, therefore, and endorsed by the Court of Appeals, derives from that irony. Governance of Büchel's work is, via its incomplete material form, a form of governance of Büchel himself.

Note, then, the contrasting lessons of the cases reviewed so far. The materiality of the garden in Kelley dominated the Court's construction of governance of that resource; the immaterial "work" all but disappeared. The materiality of the sculpture in MassMoCA was, by contrast, purely an extension of the immaterial being of the sculptor. To recognise an (intangible) work in Büchel's unfinished (material) sculpture was to recognise the whole of Büchel himself. One could no more imagine shared governance of the sculpture than one could imagine shared governance of a human being. To be sure, in the US context, treating individual identity as part and parcel of a regime of shared governance may strike the reader as a bit of unorthodox framing but not conceptually alien. "Who we are" is not entirely a matter of pure self-definition. Nonetheless, initially, at least, just that approach seems to be the kind of impermeable boundary imposed by the Court, and the kind of impermeable boundary sometimes present in other non-VARA moral rights cases in the US. In Gilliam $v$ American Broadcasting Companies, ${ }^{32}$ the integrity of the work qua work stands in for the integrity of the authors themselves. The clarity of the Court's reasoning in MassMoCA makes that case a more compelling illustration.

That summary accounts for the Court's reasoning in the case but does not exhaust questions concerning governance in this context. For example, it should not be forgotten that, despite the Court's express

32538 F. 2d 14 (2d Cir 1976). 
reasoning, the participatory elements that constitute the work in Mass$M o C A$ and access to the work include not only the artist and the audience but also the interests and claims of the institutions of the art world, embodied in the particular case by MassMoCA itself. The knowledge commons research framework teaches that one must be careful not to see the world via an author/audience duality. Here, curators, museum directors, board members, investors, donors and museum patrons all have interests in the collection, curation and presentation of the art works that make up each museum's collection. Those interests, and the legal and normative duties that accompany them, attach when works are formally part of the museum's collection and not before. ${ }^{33}$

Many of those interests are represented legally and normatively in property terms. Art institutions ordinarily are bound not to de-accession works of art from their collections except under specific circumstances. Museums and their agents may not act purely in market terms. Having accepted these works as gifts, in many cases, museums undertake to care for them in part according to a trust relationship with society as a whole, ${ }^{34}$ a relationship that aligns these institutions with the norms of gift exchange. Once a gift, always a gift, in a manner of speaking; to convert a gift into a marketable commodity is to violate the norms of gift-giving. When a work becomes formalised in the collection of a museum, therefore, the author's interest is not erased, but it is recontextualised in the context of the institution. The materiality of the sculpture represents not only the artist but also, at times, those whose financial and organisational support makes possible production, presentation and curation of the sculpture. The concept of the work in MassMoCA and in the context of the art world in general permits those two communities - artists, on the one hand, and art institutions, on the other hand - to participate constructively in the constitution of the resource, if not always without disagreeing, via a form of knowledge sharing.

\subsection{Bridgeman Art Library, Ltd v Corel Corp: Is Digital Different?}

Little in this chapter so far has touched on problems specifically associated with digital technology, which is often associated with the idea that knowledge or information works have progressed to the state of

33 For more on the intersection of copyright law and curatorial interests, see Madison, 'Knowledge Curation' (n 5) 1957.

34 See Sue Chen, 'Art Deaccessions and the Limits of Fiduciary Duty' (2009) 14 Art Antiquity \& L 103. 
being "purely" intangible. Practice teaches otherwise: digital works are neither necessarily more or less material than their analogue counterparts. But governance problems associated with digital creations are distinct, which means that conveying a fuller picture of access problems with knowledge resources should account for the different character of their digital versions. A challenging example is Bridgeman Art Library, Ltd $v$ Corel Corp, ${ }^{35}$ in which exact reproductions of public-domain paintings, marketed as transparencies and CD-ROMs, were held not to be copyrightable in a case brought against a commercial copyist. The Court concluded that works produced by the plaintiff, Bridgeman Art Library, as perfect digital copies of the original art works, did not manifest the requisite originality to be protected in copyright as derivative works, because there was no evident distinguishable variation between the source and the reproductions:

In this case, plaintiff by its own admission had labored to create "slavish copies" of public domain works of art. While it may be assumed that this required both skill and effort, there was no spark of originality - indeed, the point of the exercise was to reproduce the underlying works with absolute fidelity. ${ }^{36}$

The plaintiff's reproductions were, in effect, so good that they reflected supreme technical skill, but no creativity or artistic judgement.

Bridgeman has been the subject of extensive commentary, the best of which has expressed strong sympathy for all the multiple interests at stake: museums and other art-historical institutions that have both commercial and scholarly interests in producing and distributing art reproductions, and scholars and the public who ought not to have their ability to view and participate in the continuing construction and interpretation of public-domain works foreclosed because of modern copyrights claimed in exact reproductions. ${ }^{37}$ That matrix of interests, and the knowledge sharing that it represents, constitutes governance. The structure of governance in this instance is closely related to the structure of governance in MassMoCA, although the purposes and outcomes of governance in the two situations are quite different. In MassMoCA, managing access to the

\footnotetext{
3525 F Supp 2d 421 (SDNY 1998) [hereafter Bridgeman I].

36 Bridgeman Art Library, Ltd v Corel Corp, 36 F Supp 2d 191, 197 (SDNY 1999) [hereafter Bridgeman II].

37 See R Anthony Reese, 'Photographs of Public Domain Paintings: How, if at All, Should We Protect Them?' (2009) 34 J Corp L 1033 (proposing a limited sui generis property right applicable to art reproductions, but expressing scepticism that such a right would pass constitutional muster).
} 
original physical work was deemed by the Court to be the chief goal of the governance structure implemented by its interpretation of copyright law. In Bridgeman, access to the original physical work was deemed to be less significant than ensuring access to the creative knowledge contained within it, whether that creative knowledge was manifested to an audience via analogue or digital structures (the original paintings, or digital copies).

Even while the outcome in Bridgeman is defensible on the merits, its rhetoric and argumentative structure are discomforting, in large part because the formal structure of the law disregards some key attributes of that governance framework. For example, the rejection of "slavish copying" as a basis for a copyright claim has support in precedent. The reference stems in part from the rejection of a claimed copyright on that ground in an earlier appellate case, L Batlin \& Son, Inc $v$ Snyder ${ }^{38}-$ but is both oddly moralistic (in the sense that it expresses a moral judgement) and inconsistent with credible artistic interests. ${ }^{39}$ Even a "slavish" copy represents an investment of socially productive artistic vision and effort. ${ }^{40}$

The Court presented the case as follows. The plaintiff began with two-dimensional works of fine art: paintings, which were in the public domain. ${ }^{41}$ Despite their public-domain status, copyright law commands a conceptual distinction of intangible idea from intangible expression in each of those paintings. The latter constitutes the creative knowledge produced by each painting's author. By creating high-quality reproductions of the paintings, Bridgeman copied that intangible expression verbatim. The author's creativity was entirely unchanged in the move from canvas to photograph and CD-ROM. The change of medium made no creative difference. As the Court noted, "production of a work of art in a different medium cannot by itself constitute the originality required

38536 F. 2d 486 (2d Cir 1976).

39 The moralistic tone carried by the phrase "slavish copying" is no accident. The first reported use of the phrase took place in a District Court opinion that granted an injunction on unfair competition grounds against the producer of a "return post card folder" that copied an identical product originated by the plaintiff. See Correct Printing Co v Ramapo River Printing Co, 16 F Supp 573, 575 (SDNY 1936).

40 See Madison, 'Beyond Creativity' (n 5) 817.

41 Presumably, most, if not all, of these paintings were never protected by copyright in the first place. The plaintiff relied in part on a certificate of registration in a work collecting its digital images entitled "Old World Masters I'. Bridgeman I (n 35) 424. 
for copyright protection". ${ }^{42}$ That proposition is consistent with a bedrock copyright concept, that the copyright exists independent of any material form in which the work is fixed. ${ }^{43}$ With no creativity, there was no originality; with no originality, there was no copyright. Because the public-domain character of the original paintings was preserved, anyone in possession of relevant digital technology could see and perhaps make some use of the creative knowledge that they contain. But that creative knowledge was itself static and unchanged; to the extent that it was shared, the intangible thing did not flow from one person or place to another. Audiences who saw the original paintings in person and who saw digital reproductions of the work on screens were seeing "the same work".

In practice, are these really "the same work"? This shifts the ground of the question from law to culture; copyright law may treat these as identical even as it accepts that culture may not. But governance investigations need not honour that distinction. The knowledge commons research framework counsels taking an expansive view of resource governance, beginning with an expansive view of the relevant resource(s). The Court's story of knowledge sharing might be reframed, then, as follows, beginning with the idea (suggested above) that the physical paintings themselves might be treated as works of authorship, and that the creative knowledge in the original paintings was modified in some relevant way in the transfer to a digital format. One could treat the original paintings as knowledge objects, and reorient the knowledge sharing or governance surrounding those objects as implicating the related but distinct question of governance of their digital counterparts as a new set of knowledge objects. There were two sets of knowledge objects or resources, in other words, not just one, each with its own set of participant creators, audiences, critics, funding and distribution institutions, re-users and so on. One who views a digital reproduction of a painting experiences a different thing than one who views the original of that painting in a gallery.

42 Bridgeman II (n 36) 196 (quoting Past Pluto Prods v Dana, 627 F Supp 1435, 1441 (SDNY 1986)).

4317 USC $\$ 202$ (2012) ("Ownership of a copyright, or of any of the exclusive rights under a copyright, is distinct from ownership of any material object in which the work is embodied."). 
The difference is not simply a matter of enchanted originals and the aura of the unique work of art. ${ }^{44}$ The difference lies as much in the fact that the knowledge shared via a screen can never equal the knowledge shared via a canvas. The screen conveys a pristineness and purity that the canvas cannot; the canvas conveys a texture and intimacy that the screen cannot match. The composition of the audiences is, almost by definition, different. Relatively few people can experience the original painting on canvas. More can experience it on screen, but they require technology and facility with the technology, and may have to submit to contractual or other restrictions on subsequent use. Neither mode of participation in the work is inherently superior to the other; the flow of knowledge shared is simply different. Note that, as presented by the Court, Bridgeman begins a question of knowledge governance. The Court's opinion does not conclude it. What the governance question reveals is that different framings yield not "less access" or "more access" to the works in question, but different forms of access, probably for different purposes and with meaning for different actors, constructed via reinterpreting the character of the works themselves. "What is the thing?", or, in this instance, "what is the work?" turns not on ontological or on legal considerations, but instead on considerations of the modes of participation that one focuses on.

\section{CONCLUSION}

The emergence of new modes of digital production of knowledge has neither changed nor provided clear answers to the underlying and long-standing challenges posed by cultural systems devoted to things, referred to here as resources, namely, how to comprehend the creation, preservation and circulation of things, and their material and immaterial dimensions, in ways that both respect their idiosyncrasies and also permit their systematic integration into law and policy. What are things? How do things work? The questions are simultaneously conceptual and empirical. This chapter has focused on their empirical dimensions, suggesting a research framework grounded in the concept of knowledge commons, or the study of institutionalised sharing of knowledge resources. Institutionalised sharing is, of course, a mode of governance. The chapter offers

44 See Walter Benjamin, 'The Work of Art in the Age of Mechanical Reproduction' (1936) in Hannah Arendt (ed.) and Harry Zohn (trans), Illuminations (Schocken Books 1968) 217. 
three preliminary sketches of knowledge commons governance, drawn from problematic cases from US copyright law.

Governance, and its concerns with documenting and describing knowledge sharing in various forms, does not necessarily lead to clear, logical, well-delineated outcomes or rules. "Structures of participation" and "entanglement", the non-legal metaphors for interactions among humans and things that I noted at the outset of this chapter, hint at the messiness that unfolds in the illustrations provided. The illustrations are only a start; no one of these cases tells us anything generalisable about things or resources or their material or immaterial dimensions. With sufficient space, the knowledge commons framework may be applied at greater length to each of these cases and, with a sufficiently large collection of cases, one could hope to discern patterns and therefore generalisable propositions regarding law and culture. 